\title{
CONCESSĀO DE SERVIÇOS PÚBLICOS DE LIMPEZA URBANA
}

\author{
MARÇAL Justen Filho* \\ Cesar A. Guimarães Pereira**
}

\begin{abstract}
I - Apresentação - II. - Breve consideração sobre o conceito de "serviço público" - III. O serviço público de coleta e destinação final de lixo - IV. - Concessão dos serviços públicos de limpeza urbanaIV.1. - Serviços delegáveis a particulares - IV.2 - Remuneração pela prestação específica do serviço - V. - Competência legislativa e administrativa para a disciplina e a concessão dos serviços de limpeza urbana - VI. - Contraprestação pelos serviços de limpeza urbana nos regimes de concessão e de contratação de serviços - VII. - Destinação específica de receita de imposto - VIII. - Conclusões
\end{abstract}

\section{I. - Apresentação}

O presente estudo destina-se ao exame da possibilidade de concessão dos serviços públicos de limpeza urbana, compreendendo tanto a coleta domiciliar de lixo quanto a limpeza de áreas públicas, a remoção e a destinação final de resíduos sólidos.

Essa análise pressuporá uma definição inicial das noções de serviço público e das características públicas dos serviços de limpeza urbana. Exigirá, ainda, o exame da possibilidade jurídica da concessão de tais serviços, tanto sob o ângulo de sua delegabilidade (em vista de tratar-se de serviços de natureza essencial) quanto da viabilidade de instituição de tarifas destinadas à remuneração do concessionário.

O estudo incluirá o exame de questões complementares, algumas relacionadas com a competência legislativa e administrativa para a concessão e a regulação dos serviços de limpeza urbana e outras vinculadas a alternativas para o financiamento da realização de tais serviços por pessoas privadas.

* Professor Titular da UPPR. Doutor em Direito pela PUC/SP. Sócio de Justen e Associados Sociedade de Advogados.

** Mestre em Direito pela PUC/SP. Sócio de Justen e Associados - Sociedade de Advogados.

R. Dir. Adm.,

Rio de Janeiro, 219: 271-292, jan./mar. 2000 


\section{II. - Breve consideração sobre o conceito de "serviço público"}

1. A qualificação de um serviço como público depende da sua publicatio, ou seja, da edição de norma (constitucional ou legal) que submeta o serviço a regime de direito público, atribuindo sua titularidade ao Estado. O tema tem sido objeto de contínuo exame por parte da doutrina.

1.1. É sempre lembrada a definição de serviço público formulada por CELSO ANTÔNIO BANDEIRA DE MELLO: "toda atividade de oferecimento de utilidade ou comodidade material fruivel diretamente pelos administrados, prestado pelo Estado ou por quem lhe faça as vezes, sob um regime de direito público - portanto consagrador de prerrogativas de supremacia e de restrições especiais - instituído pelo Estado em favor de interesses que houver definido como próprios no sistema normativo"'.

Sobre o mesmo tema, um dos autores teve a oportunidade de mencionar a instrumentalidade do serviço para a realização dos fins da comunidade como limite para a definição normativa de um serviço como público (publicatio). Essa constatação deriva de que a atribuição da titularidade de certos serviços ao Estado traduz uma determinada percepção da coletividade sobre o modelo de Estado e os valores jurídicos fundamentais. Como então exposto, "O conceito de serviço público é um conceito reflexo. Deriva do modelo constitucional assumido pela comunidade, inclusive no tocante à função e ao papel que a própria comunidade reserva para si própria" 2 .

1.2. Ou seja, certos serviços são necessariamente públicos, não sendo passíveis de despublicatio. São aqueles de mais intenso vínculo com a dignidade da pessoa humana - valor fundamental que condiciona a compreensão da integralidade do ordenamento jurídico.

Como já escrito por um dos autores, uma consideração inafastável acerca do serviço público "relaciona-se com sua aptidão para realizar certos valores fundamentais assumidos pela Nação. Bem por isso, é impossivel despublicizar certos serviços públicos no Brasil, pois sua prestação foi garantida constitucionalmente, como via de promover a dignidade da pessoa humana, a eliminação das desigualdades e outros valores fundamentais. Não se admite que o Estado se recuse a promover tais valores, nem mesmo diante da invocação de ausência de lucratividade. Aliás, há serviços que são transformados em públicos precisamente porque, em face dos encargos a eles relacionados, nunca seriam desempenháveis pela iniciativa particular, tendo em vista sua incompatibilidade com os parâmetros de lucratividade que norteiam a atuação tipicamente privada" ${ }^{3}$.

1 Curso de Direito Administrativo, Malheiros, $11^{\mathrm{a}}$ ed., p. 477.

2 MARÇAL JUSTEN FILHO, Concessão de Serviços Públicos, Dialética, 1997, p. 58.

3 JUSTEN, ob. cit., p. 59. 


\section{O serviço público de coleta e destinação final de lixo}

3. As atividades de coleta e destinação final de lixo doméstico e industrial pressupõem infra-estrutura material - representada por usinas de compostagem ou reciclagem, aterros sanitários, unidades de desinfecção, incineradores e outros equipamentos necessários para a destinação final dos resíduos. Tais obras são meramente instrumentais (o suporte material) para a prestação dos serviços. O núcleo da noção de limpeza urbana está na realização de um serviço (ou seja, de uma prestação correspondente a um "fazer", segundo a classificação tradicionalmente consagrada no âmbito da Teoria Geral do Direito).

Além disso, os serviços de coleta e destinação final de lixo estão dentre os mais diretamente ligados à realização da dignidade da pessoa humana.

4. É relevante destacar que coleta, transporte e destinação final de lixo não se realizam no interesse exclusivo do beneficiário imediato do serviço (o responsável pela produção do lixo). Ou seja, a pessoa que produz o lixo tem interesse na coleta e destinação final dos resíduos. Mas a necessidade dos serviços não se exaure no âmbito individual.

4.1. Os serviços de lixo vinculam-se à promoção da saúde pública e à preservação do meio ambiente - condições essenciais para a vida humana digna. São atividades abrangidas no conceito amplo de saneamento básico, cuja melhoria é prevista como de competência comum dos entes políticos (art. 23, IX, da Constituição de 1988). Nesse sentido, ALAÔR CAFFÉ ALVES aponta que "no conceito de 'Saneamento Básico', seja funcional ou estruturalmente concebido, incluem-se ou podem ser incluídos as ações, serviços e obras referentes à coleta, transporte, reaproveitamento, tratamento e disposição de resíduos sólidos, tendo por objetivo alcançar niveis crescentes de salubridade ambiental" 4 .

Por se enquadrarem no conceito de saneamento básico, os serviços de remoção e destinação final de lixo configuram-se como públicos por definição constitucional.

4.2. Lembre-se, ademais, que a destinação do lixo tem efeitos diretos com a preservação do meio ambiente. $\mathrm{O}$ acúmulo de dejetos é nocivo às condições de salubridade. A ausência de tratamento adequado aos dejetos produz a degradação das condições ambientais, pondo em risco a fauna, a flora e outros elementos vitais ao ser humano. As atividade referidas envolvem a realização da preservação ambiental, o que pressupõe técnicas de destinação dotadas de viabilidade econômica e de sustentabilidade. Além disso, e principalmente, são implementadas atividades de prevenção na produção de resíduos, evitando-se que venham a ser necessárias a coleta e a destinação final do lixo. O desenvolvimento de tais atividades é dever do Poder Público na forma do art. 225 da Constituição de 1988.

Ainda sob esse ângulo, os serviços de lixo podem ser enquadrados nos temas de competência comum (art. 23, VI, da Constituição de 1988) e concorrente (art. 24, VI, da Constituição de 1988) dos entes da Federação. Trata-se, também por essa via, de atividades sob a responsabilidade do Poder Público de todos os entes da 
Federação (embora afeta de modo mais imediato aos Municípios, na forma do art. 30, V, da Constituição de 1988). Não seria adequado, neste momento, ingressar na análise da titularidade do aludido serviço público, mas deve ter-se em vista a pluralidade de órbitas de interesses potencialmente envolvidas em tema dessa ordem.

4.3. Mas o tratamento jurídico da questão não pode ser desvinculado do conceito amplo de "saúde pública". A deficiência nos serviços de coleta e destinação do lixo propiciam riscos de moléstias, endemias e epidemias. $\mathrm{O}$ descuido com o lixo repercutirá na qualidade de vida do grupo, em seu todo.

Sob o ângulo da vinculação de tais serviços à proteção da saúde pública, o art. 197 da Constituição de 1988 estabelece que "são de relevância pública as ações $e$ serviços de saúde, cabendo ao Poder Público dispor, nos termos da lei, sobre sua regulamentação, fiscalização e controle, devendo sua execução ser feita diretamente ou através de terceiros, e também, por pessoa física ou jurídica de direito privado". $\mathrm{O}$ art. 200 da Constituição prevê expressamente que compete ao sistema único de saúde "participar da formulação da política e da execução das ações de saneamento básico" e "colaborar na proteção do meio ambiente, nele compreendido o do trabalho".

4.4. Como se vê, os serviços de lixo enquadram-se no conceito de serviços públicos, sob diferentes perspectivas. Aliás, o art. $2^{\circ}$ da Lei no 9.074 , de 7.7.1995, reconhece essa qualidade, ao dispor sobre a possibilidade de sua concessão. Independentemente de eventuais críticas ao dispositivo, ali se retrata a inequívoca publicatio dos serviços de limpeza urbana. Nesse sentido, confira-se MARCílLIO TOSCANA FRANCA FILHO

5. A publicização de tais serviços não significa a completa impossibilidade de sua prestação em regime diverso do de direito público.

5.1. Podem ser identificados diferentes graus de proximidade entre as atividades específicas de limpeza urbana e a dignidade da pessoa humana, a proteção da saúde pública e a proteção ao meio ambiente. Certas atividades somente podem ser prestadas sob regime de direito público - inclusive por envolver serviços que exijam universalização ou por exigir dispêndios (realizados no interesse coletivo de proteção do meio ambiente, por exemplo) não compensáveis economicamente pela exploração da atividade. Outras admitem sua prestação em regime de competição, sujeita a regras de direito privado (ainda que também à regulação e à prévia autorização do ente político competente).

5.2. Nessa linha, e sem qualquer consideração à natureza jurídica do instrumento utilizado (ou à validade da regra veiculada), o art. $4^{\circ}$ da Resolução $n^{\circ}$ 5, de 5.8.1993, do Conselho Nacional do Meio Ambiente - CONAMA prevê caso de prestação de serviço de limpeza urbana sob regime competitivo.

A Resolução dispõe acerca dos resíduos sólidos gerados em portos, aeroportos, terminais ferroviários e rodoviários e estabelecimentos prestadores de serviços de saúde $\left(\right.$ art. $\left.2^{\circ}\right)$. No seu art. $4^{2}$, dispõe que "caberá aos estabelecimentos já referidos o gerenciamento de seus resíduos sólidos, desde a geração até a disposição final,

5 "Contrato de Concessão e Limpeza Pública", em $D C A P / I O B \mathrm{n}^{\mathrm{Q}} 7$ (julho de 1999), p. 27. 
de forma a atender aos requisitos ambientais e de saúde pública". Incumbiria a tais entidades promover diretamente ou através de terceiros a remoção e a destinação final de tais resíduos sólidos. A atuação do Poder Público, neste caso, seria meramente subsidiária e se desencadearia apenas na ausência de atuação dos particulares (cuja omissão configura ilicitude), tendo em vista o interesse coletivo na adequada disposição dos resíduos.

Essa é uma alternativa que se põe à análise jurídica, seguindo uma tendência mais ampla de responsabilização do particular que produz especiais encargos para a Administração Pública.

6. Nada impede, porém, que uma lei local venha a publicizar a totalidade das atividades relacionadas com a remoção e a disposição final de resíduos de qualquer natureza.

O alcance da publicização é definido a partir da opção legislativa por um grau de intervenção estatal na prestação de tais serviços. Através dessa opção legislativa, o Poder Público compromete-se frente à coletividade a realizar determinadas atividades. A publicização de tarefas corresponde à assunção, pelo Poder Público, do dever de promover a sua realização.

7. Em linhas gerais, portanto, os serviços de remoção e destinação final de resíduos sólidos (lixo) configuram serviços públicos. Têm natureza essencial e devem ser prestados com caráter de universalidade. São previstos normativamente como objeto de um dever do Poder Público. Consistem materialmente em prestações (realização de atividades) fruíveis diretamente pelas pessoas produtoras de resíduos, que correspondem aos usuários dos serviços de remoção e destinação final de lixo.

Como será visto adiante, a estipulação de contraprestação pela realização de tais serviços (seja através de taxa ou de tarifa) atende ao princípio da isonomia ao fazer recair o encargo econômico da atuação estatal sobre aquele que a provoca de modo mais intenso. Além disso, realiza o princípio do poluidor pagador ("aquele que polui, paga"), traduzido no art. 225 , $\S \S 2^{2}$ e $3^{2}$, da Constituição de 1988 , permitindo que se exija diretamente de quem produz os resíduos o custeio (ao menos parcial) da atividade estatal necessária para a gestão de tais resíduos.

\section{IV. - Concessão dos serviços públicos de limpeza urbana}

8. Como decorrência, aplica-se aos serviços examinados a regra do art. 175 da CF/88. O dispositivo determina que os serviços públicos serão prestados pelo Estado, diretamente ou mediante concessão ou permissão. O dispositivo tem de interpretar-se em termos, eis que existem serviços públicos que não comportam delegação a particulares.

Cabe definir, portanto, se os serviços ora examinados somente podem ser prestados diretamente pelo Poder Público ou também sob regime de concessão ou permissão.

Essa definição pressupõe o exame de duas questões. Em primeiro lugar, deve-se verificar se a essencialidade e a compulsoriedade dos serviços de remoção e destinação final de lixo impedem a sua prestação por pessoa não integrante da Adminis- 
tração Pública. Depois, deve-se investigar se os serviços de remoção e destinação final de lixo permitem a percepção, pelo concessionário, de receita própria (derivada de tarifas ou de outras fontes) independente de custeio direto pelo Poder Público.

\section{IV.1. - Serviços delegáveis a particulares}

9. Um primeiro tópico a ser examinado em relação à possibilidade de concessão de serviços públicos de remoção e destinação final de lixo diz respeito à essencialidade e à compulsoriedade de tais serviços.

Afirma-se que, por ser essenciais, tais serviços são de prestação obrigatória pelo Poder Público. A contrapartida da compulsoriedade na sua prestação seria a compulsoriedade em sua utilização (como referido pelo Supremo Tribunal Federal em julgado publicado na $R T J$ 98/230). Pode-se pretender levar o raciocínio à conseqüência de que, sendo compulsórias a sua prestação e a sua utilização, o serviço não poderia ser objeto de concessão por não se poder submeter um particular à utilização e à remuneração compulsórias de serviço prestado por outro particular.

Não se afigura ser essa a melhor solução. A essencialidade e a compulsoriedade na prestação e na utilização do serviço não são obstáculos à sua concessão. A outorga de concessão é forma de regulação da prestação de serviços públicos. Através da concessão, o Poder Público define metas e critérios de fiscalização, disciplinando a realização de determinado serviço. A existência de maior relevância social do serviço apenas conduz à consagração de metas e critérios mais estritos e rigorosos.

Desde logo, diga-se que nada impede que a prestação de serviços de utilização compulsória seja remunerada através de tarifas, não de taxas. A compulsoriedade do serviço não transforma em tributo a remuneração pela prestação do serviço. Sobre isso, voltar-se-á abaixo a exame.

\section{IV.2 - Remuneração pela prestação específica do serviço}

10. A concessão de serviço público se caracteriza, dentre outros pontos, pela ausência de remuneração do prestador do serviço diretamente pela Administração Pública. Ao contrário da contratação de serviços pela Administração, a concessão envolve a assunção de riscos pelo concessionário. A existência de remuneração promovida ou assegurada pela Administração Pública desnatura a concessão. Somente será viável a outorga de concessão na medida em que seja cabível, pela configuração da atividade a ser explorada, a percepção de receita pelo concessionário de modo desvinculado da Administração Pública.

Aliás, a garantia de remuneração mínima pela Administração Pública (ainda que de forma indireta, mediante pagamentos que eliminem ou reduzam os riscos da concessão) é proibida em face do veto presidencial ao art. 24 da Lei ${ }^{0}$ 8.987/95.

Isso não significa que a única fonte de receita do concessionário tenha de ser a tarifa. Outras fontes (alternativas ou acessórias) podem ser cogitadas. Assim, por 
exemplo, a exploração de publicidade nas margens de rodovia pode fazer-se pelo concessionário da rodovia.

11. Note-se que, na generalidade dos casos envolvendo lixo, a viabilidade da concessão pressupõe a cobrança de tarifas. As receitas alternativas (p. ex., venda de lixo reciclável, de produtos de compostagem e publicidade) são secundárias, na acepção de insuficientes para produzir remuneração compatível com a dimensão das despesas (embora tenham grande relevância ambiental).

12. O primeiro problema a examinar, nesse tópico, consiste na possibilidade jurídica de submeter os trabalhos de coleta e destinação do lixo a uma remuneração específica, a ser paga por alguns dos integrantes da coletividade.

Essa questão tem preocupado doutrina e jurisprudência. Mais recentemente, um dos autores enfrentou o tema em artigo intitulado "Participação Privada nos Serviços de Limpeza Urbana"6.

12.1. Afigura-se que o exame do tema tem de partir dos princípios constitucionais fundamentais. A exigência de pagamento como contrapartida da prestação de serviços de lixo realiza o princípio da isonomia?.

Ou seja, a coleta do lixo (e demais atividades daí derivadas) não são nunca prestadas gratuitamente. O custeio dessas atividades ou se faz por toda a coletividade ou recairá sobre determinadas pessoas (aquelas que produzem o lixo). $\mathrm{Na}$ ausência de cobrança de tarifa (ou de taxa), o custo correspondente é suportado pelas receitas públicas gerais. Ou seja, é distribuído aos integrantes da coletividade sob a forma de impostos (tributos não vinculados a uma atuação estatal). Isso representa, em última análise, impor um ônus desequilibrado entre os membros da coletividade. Aquele que não gera lixo, que não desenvolve atividades poluidoras, terá de arcar com despesas necessárias à limpeza dos dejetos produzidos pelos poluidores.

Ora, afigura-se que a única solução compatível com o princípio da isonomia é aquela que responsabiliza especificamente o produtor do lixo. A isonomia, no caso, conjuga-se com o princípio da solidariedade, todos consagrados nos arts. $1^{\mathrm{Q}}$ e $3^{\mathrm{Q}} \mathrm{da}$ CF/88. Não se pode admitir que os poluidores nada paguem (ou paguem tanto quanto os não poluidores). Isso corresponde à ausência de solidariedade social. $O$ sujeito que produz lixo tem o dever de solidariedade de responder em face dos demais cidadãos, realizando algum tipo de atividade que compense os demais pelos prejuízos acarretados.

12.3. Não se pode deixar de mencionar, por outro lado, que a exigência de tarifa (ou de taxa) pela prestação de serviços de remoção e destinação final de lixo realiza o princípio do poluidor-pagador (já referido em tópico anterior).

Os serviços de remoção e destinação final de lixo transcendem o interesse individual do usuário (o produtor do lixo). Quando muito, pode-se cogitar da existência de interesse particular do usuário na remoção do lixo. Não é imaginável, porém, um interesse egoístico do particular produtor do lixo em que a sua destinação

6 CESAR A. GUIMARĀES PEREIRA, "Participação Privada nos Serviços de Limpeza Urbana", Revista de Direito Administrativo n² 216, abril/junho de 1999, pp. 75/108.

7 PEREIRA, ob. cit., p. 100. 
ocorra do modo ambientalmente mais adequado (uma vez que essa forma de destinação tende a corresponder à economicamente mais custosa). $O$ interesse tutelado através da destinação adequada do lixo é o da coletividade, não o interesse particular do produtor do lixo. Mesmo no caso da mera remoção, há inegável interesse coletivo. Não será dado ao particular produtor do lixo mantê-lo em depósito inadequado, transportá-lo sem as cautelas cabíveis nem dar-lhe destinação incompatível com as diretrizes públicas.

Essa conjugação de interesses conduz ao sopesamento de dois princípios na definição da responsabilidade do produtor do lixo pelo custeio da atividade estatal de remoção e destinação final dos resíduos. De um lado, busca-se exigir de quem produz os resíduos (e torna necessária a sua eliminação) o pagamento de montante correspondente à atuação da Administração Pública (ou de concessionário de tais serviços públicos). De outro, limita-se a responsabilidade do produtor dos resíduos em face da existência de um interesse coletivo na gestão adequada do lixo produzido. Conjuga-se o princípio do poluidor-pagador com o princípio do ônus social ${ }^{8}$.

12.4. A relevância da matéria não se restringe aos limites nacionais. A questão tem sido objeto de exame em todos os países do mundo, com experiências eventualmente aplicáveis ao Direito pátrio. Pode lembrar-se, a propósito, a Resolução do Conselho da Europa de 24 de fevereiro de 1997, que "considera que com relação aos princípios de 'quem contamina, paga' e de responsabilidade compartilhada, todos os agentes econômicos devem encarregar-se de sua parte específica de responsabilidade no que se refere à prevenção, valorização e eliminação de resíduos" 9 .

12.5. Enfim, todos os países do mundo (ocidental, especialmente) enfrentam a temática do "lixo". A seriedade do problema, em uma sociedade elevadamente industrializada, impede que seja considerado como mera e simples "parte das atribuições comuns do Estado". Tem de estabelecer-se um vínculo entre a produção do lixo e a responsabilização do agente. A dificuldade na apuração desse vínculo não deve resolver-se na pura e simples generalização do pagamento - o que se traduzirá em elevação genérica da carga tributária sobre todos os integrantes da sociedade.

13. Outra é a questão da "identificação" do sujeito poluidor. Em alguns casos, tal poderá fazer-se de modo mais simples e evidente (produção de lixo industrial, por exemplo). Mas há a situação do lixo domiciliar, em que não há possibilidade de identificação externa do lixo gerado. Correlato a esse é o problema do dimensionamento do lixo produzido (tanto sob os ângulos qualitativos como quantitativos), para fins de fixação de uma remuneração correspondente.

O tema foi enfrentado no já referido estudo de um dos autores. Tal se fez a propósito do exame da jurisprudência do Supremo Tribunal Federal e do Superior

8 Sobre o sopesamento de tais princípios, confira-se CRISTIANE DERANI, Direito Ambiental Econômico, Ed. Max Limonad, 1997, p. 161.

9 FRANCISCO JAVIER SANZ LARRUGA, "La Nueva Legislación de Residuos. Especial Referencia a los Residuos Sanitarios", em Lecciones de Derecho Sanitario, Ed. Universidad de Coruña, 1999, p. 365. 
Tribunal de Justiça acerca da especificidade e da divisibilidade dos serviços relacionados com a taxa de limpeza urbana, mediante a análise dos julgamentos proferidos no Recurso Extraordinário no ${ }^{199.969-1 / S P}$ (STF) e nos Embargos de Divergência $\mathrm{n}^{\mathrm{O}}$ 102.404/SP (STJ). No primeiro caso, o voto vencedor do relator (Min. Ilmar Galvão) apontava que tais serviços correspondem a "atividade estatal de caráter uti universi, destinada ao benefício da população em geral, não podendo tais prestações de serviço ser destacadas em unidades autônomas, nem permitindo a individualização sua área de intervenção, além de não se apresentarem suscetíveis de utilização separada, por parte de cada um de seus usuários". No precedente do Superior Tribunal de Justiça, reconheceu-se que legislação municipal de São Paulo previa a taxa como remuneração - " além dos serviços de 'remoção de lixo domiciliar' outros que não aproveitam especificamente ao contribuinte ('varrição, lavagem e capinação', 'desentupimento de boeiros e bocas-de-lobo'); ademais, a respectiva base de cálculo não está vinculada a atuação estatal, valorizando fatos incapazes de mensurar-lhe o custo (localização, utilização e metragem do imóvel) - tudo com afronta aos arts. 77, caput, e 79, inc. II, do CTN'.

Deve-se atentar para a circunstância ${ }^{10}$ de que essa orientação jurisprudencial recente baseia-se em precedente relacionado com lei municipal que elegera como critério de repartição do custo do serviço a área ou a testada de cada imóvel existente no território do município. Assim, o fundamento para a decretação da invalidade da lei municipal que instituiu a taxa de limpeza urbana pode ter sido antes a escolha inadequada de um critério de identificação do usuário e de medição do serviço utilizado que a impossibilidade técnica de existir critério apropriado para esses fins.

De todo o modo, a definição do montante individual da tarifa (o que pressupõe a viabilidade de identificação de um usuário individual) é informada por um princípio de praticabilidade. Deve haver composição equilibrada entre a certeza quanto à identificação do usuário e a medição da quantidade de serviço utilizada e a necessidade da cobrança da tarifa. Esses fatores devem ser combinados de forma que nem a certeza nem a necessidade sejam integralmente sacrificadas. Devem-se adotar presunções construídas sobre indícios relevantes, de forma a simplificar e tornar mais razoável a instituição da tarifa.

Nos últimos meses, a jurisprudência do Supremo Tribunal Federal vem-se inclinando pelo reconhecimento da possibilidade de instituição de taxas vinculadas ao serviço de coleta domiciliar de lixo (resíduos sólidos). Nesse caso, não haveria discussão acerca da ausência de especificidade ou divisibilidade dos serviços. Por conseguinte, não se cogitaria de qualquer dificuldade na identificação de usuário responsável pelo pagamento da tarifa correspondente.

Nesse sentido, confira-se precedente recente do $S_{T F}{ }^{11}$, relacionado com lei municipal de Campinas (SP) que instituía, entre outras, taxa tendo por hipótese de incidência " a utilização, efetiva ou potencial, do serviço de coleta, remoção $e$

10 Complementar em PEREIRA, ob cit., pp. 99/100.

11 RE n² 233.784-4/SP, $1^{2}$ T., Rel. Min. Ilmar Galvão, v.u., j. 10.8.1999, publ. DJU de 12.11.1999, p. 114, e Revista Dialética de Direito Tributário (RDDT) n² 52, pp. 185/186. 
destinação de lixo, prestado ao contribuinte ou posto à sua disposição". A quantificação da taxa baseava-se na combinação entre a frequiência da prestação do serviço e a testada do imóvel' ${ }^{12}$. O precedente assentou que as taxas foram "legitimamente instituidas como contraprestação a serviços essenciais, específicos e divisíveis, referidos ao contribuintes a quem são prestados ou a cuja disposição são postos, não possuindo base de cálculo própria de imposto" ${ }^{13}$.

14. A título de conclusão, deve considerar-se como perfeitamente cabível a concessão do serviço público de coleta e destinação do lixo, ainda quando seja necessária adoção de instrumentos indiretos de avaliação da responsabilidade pelo custeio dos ditos serviços.

\section{V. - Competência legislativa e administrativa para a disciplina e a concessão dos serviços de limpeza urbana}

15. Os serviços de remoção e destinação final de resíduos sólidos são considerados como tipicamente municipais. Enquadram-se na previsão do art. 30, V, da Constituição de 1988 como serviços de interesse local. Em princípio, compete aos Municípios a disciplina e a execução de tais serviços, ainda que sob regime de concessão ou permissão.

Porém, essa competência não é privativa. Por se tratar de serviços relacionados com a proteção do meio ambiente, são objeto de competência comum e concorrente entre os entes políticos (o que submete os Municípios a normas gerais eventualmente editadas pela União e à interação administrativa com a União e os Estados). De outro lado, o vínculo entre a limpeza urbana e a saúde pública torna cabíveis a edição de lei federal sobre normas gerais a ser observadas pelos Municípios e a participação do SUS na execução de ações de saneamento básico (inclusive de remoção e destinação final de lixo).

Além disso, os serviços de limpeza urbana podem assumir, por razões técnicas ou econômicas, configuração que ultrapassa os limites do território de um Município.

Nesses casos, os serviços de remoção e destinação final de lixo passam a envolver uma conjugação de interesses de vários Municípios, seja para a prestação direta dos serviços, seja para a outorga de sua exploração sob regime de concessão.

Um dos autores já teve oportunidade de examinar esta questão a respeito dos serviços de abastecimento de água que afetassem mais de um Município, apontando que a solução tradicional (concessão outorgada a entidade da administração indireta estadual) configurava concessão imprópria ou um convênio entre os entes públicos. A premissa então adotada (válida também para este caso) era a de que, respeitados os princípios fundamentais norteadores do sistema jurídico, a existência dos convênios decorre do postulado de que a competência é outorgada a diversos sujeitos políticos autônomos, mas para a realização de um único interesse público. Na sua 
pluralidade, esses entes podem (devem) atuar conjugada e harmonicamente para multiplicação de esforços e realização mais eficiente dos interesses comuns" ${ }^{4}$.

FLORIANO AZEVEDO MARQUES NETO, examinando questão similar, concluiu ser viável a um conjunto de municípios, reunidos em consórcio, promover em conjunto a outorga de contrato de concessão de serviço de limpeza urbana ${ }^{15}$. Conforme já assentado por um dos autores, a nova redação do art. 241 da Constituição de 1988 também permite concluir que as regras acerca da autonomia municipal devem ser interpretadas de modo a possibilitar que, autorizado por lei, o município integre consórcios ou celebre convênios para o exercício compartilhado do poder concedente ${ }^{16}$.

16. As competências comum e concorrente dos entes políticos neste campo podem ser exercidas através da instituição de agência reguladora federal ou estadual, com competência para regular (nos limites da competência de cada ente político) a organização dos serviços de limpeza urbana e integrar as atividades dos Municípios nos pontos em que possam afetar os interesses de outros.

Um dos autores já escreveu que "Outra possibilidade de solução do problema consistiria na definição dos conjuntos de municípios como regiäo metropolitana, aglomeração urbana ou microrregião. Nesse caso, a competência para a concessão dos serviços poderia ser estabelecida na forma do art. $25, \S 32$, da Constituição Federal, através de lei complementar estadual" "1?. ALAÔR CAFFÉ ALVES examina o tema e conclui que o exercício de tais atividades que produzem impacto sobre o "meio ambiente urbano-regional" é "peculiar, visto que os Municípios não poderāo exercê-las de modo isolado, senão conjuntamente, numa espécie de co-gestão entre eles e o Estado que tem a responsabilidade de organizá-las originariamente, mediante lei complementar. Neste caso se incluem, como funções públicas de interesse comum, as ações de saneamento básico ou ambiental em regiōes metropolitanas, aglomeraçōes urbanas e microrregiōes, criadas por lei complementar estadual, dentre tais funçōes se elencam as açōes públicas do subsetor de resíduos sólidos" 18 .

17. A questão da competência administrativa, nos casos de serviços que ultrapassem os limites territoriais de um Município, deve ser solucionada mediante critério formal.

Não havendo a definição de regiões metropolitanas ou outros agrupamentos através de lei complementar estadual, a competência administrativa para a realização das atividades de limpeza urbana é atribuída aos Municípios envolvidos, na forma do art. $30, \mathrm{~V}$, da Constituição de 1988 . Nesse caso, a participação da União e dos Estados na disciplina e na concretização de tais serviços será restrita ao que lhes cabe no exercício da competência comum e concorrente. A outorga de concessão

14 JUSTEN, ob. cit., p. 75.

15 "Outorga de Concessão de Serviços de Limpeza Urbana por Consórcio Intermunicipal”, em Boletim de Direito Administrativo, v. 13, n² 10, pp. 681/687, outubro de 1997.

16 PEREIRA, ob. cit., p. 94.

17 PEREIRA, ob. cit., p. 94.

18 Ob. cit., p. 283. 
pressuporá, se for o caso, ato praticado de modo conjugado pelos Municípios titulares da competência administrativa para a realização de tais serviços.

VI. - Contraprestação pelos serviços de limpeza urbana nos regimes de concessão e de contratação de serviços

18. Tem-se discutido acerca do instrumento jurídico de remuneração do concessionário (taxa ou tarifa). A discussão conduziu à edição da Súmula $\mathrm{n}^{\mathrm{Q}} 545$ do STF, pela qual "Preços de serviços públicos e taxas não se confundem, porque estas, diferentemente daquelas, são compulsórias e têm sua cobrança condicionada à prévia autorização orçamentária, em relação à lei que as instituiu".

18.1. Lembre-se que essa Súmula foi editada há longo tempo, ainda na vigência da Constituição de 1946, que adotava sistemática totalmente diversa para o sistema tributário. Rigorosamente, a melhor solução seria considerá-la como superada (com a devida venia ao Colendo STF, único titular da competência para revogá-la formalmente).

Apesar disso, a Súmula foi aplicada, em 1980, para considerar inconstitucional "tarifa de lixo" (no RE no 89.876/RJ, RTJ 98/230). A orientação do Supremo Tribunal Federal baseava-se em dispositivo equivalente ao atual art. 145, II, da Constituição de 1988, e correspondia, em linhas gerais, à concepção de MARCO AURÉLIO GRECO e GERALDO ATALIBA sobre o tema. Na medida em que a regra constitucional vinculava a prestação de serviços públicos específicos e divisíveis à cobrança de taxa, não se reputou possível que essa mesma categoria de serviços ensejasse cobrança de outra natureza (tarifa ou preço público).

18.2. Lembre-se que a referência à compulsoriedade constante da Súmula não se vincula ao dever de pagar, já que ambas as formas de cobrança são objeto de um dever jurídico. Relaciona-se com a utilização do serviço. Os serviços de utilização compulsória seriam sempre objeto de taxa; os serviços de utilização não compulsória poderiam ser objeto de tarifa quando prestados por entes não integrantes da Administração direta ou taxa quando prestados diretamente pelo Poder Público.

19. Mas a evolução doutrinária acabou por refutar essa concepção. A solução do tema se relaciona com a garantia constitucional à equação econômico-financeira da concessão, tal como prevista na regra constante do art. 175 da Constituição de 1988 (que já constava, na essência, da Constituição anterior).

19.1. O regime da concessão de serviços públicos pressupõe a possibilidade de alteração de tarifa a qualquer tempo, como instrumento para a manutenção do equilíbrio econômico-financeiro. Por isso, um dos autores já defendeu que "o regime tributário é incompativel com o regime jurídico da remuneração do concessionário (permissionário). Quando o Estado outorga concessão, não se altera o regime jurídico da prestação do serviço público, mas se modifica o regime jurídico de sua remuneração. A Constituição Federal, ao tutelar a intangibilidade da equação econômico-financeira do contrato administrativo, produz uma espécie de redução da amplitude eficacial do sistema tributário. Retira do seu âmbito a remuneração 
atinente aos serviços públicos outorgados aos particulares por via de concessāo ou permissäo" 19 .

O art. 175 da Constituição, que prevê a possibilidade de prestação de serviços públicos sob regime de concessão, e o art. 37, XXI, da Constituição, que assegura a manutenção da equação econômico-financeira dos contratos de concessão, excepcionam o art. 145, II, da Constituição quanto ao regime jurídico da remuneração do concessionário do serviço público. A remuneração passa a ter a natureza de tarifa (não tributária).

19.2. Pode afirmar-se, então, que a qualificação da remuneração do concessionário como tarifa não tem nenhum vínculo com a eventual compulsoriedade na utilização dos serviços que ensejam a sua cobrança. Os deveres de utilizar o serviço e o de pagar a tarifa correspondente são distintos e dissociados entre si. A exigência da tarifa deriva da tutela de interesses diversos, relacionados com a intangibilidade da equação econômico-financeira do contrato de concessão. Na medida em que sejam concedidos serviços de utilização compulsória, a sua prestação não se poderá fazer com o sacrifício do concessionário. Será imperiosa, nesse caso, a qualificação da remuneração como tarifa a fim de preservar o regime jurídico da concessão.

Já se apontou que a compulsoriedade na utilização do serviço é reflexo da compulsoriedade na sua prestação pelo Poder Público. A obrigatoriedade de prestação não importa, porém, em proibição de oferta do serviço sob regime de concessão.

19.3. É usual opor-se a esse raciocínio o dispositivo do art. $7^{\circ}$, III, da Lei $n^{e}$ 8.987. Em sua redação original (posteriormente alterada), a regra estabelecia ser direito do usuário "obter e utilizar o serviço, com liberdade de escolha, observadas as normas do poder concedente". O dispositivo supostamente estabelecia uma necessária facultatividade na utilização do serviço objeto de concessão.

Porém, o art. 7º, III, da Lei no 8.987 não estabeleceu liberdade plena de escolha por parte do usuário dos serviços conce' ' dos. Não se presta como argumento acerca da impossibilidade de a lei tornar obrigáuria a utilização do serviço concedido.

O primeiro ponto relevante é a modificação da redação do dispositivo pela Lei $\mathrm{n}^{2}$ 9.648. A nova redação da regra passou a prever o direito de "obter e utilizar $o$ serviço, com liberdade de escolha entre vários prestadores de serviço, quando for o caso, observadas as normas do poder concedente". O próprio texto da lei restringiu a noção de liberdade de escolha para torná-la aplicável apenas na hipótese de haver vários prestadores, quando o usuário poderia optar por qualquer deles.

Além disso, o art. $9, \S 1^{\circ}$, da Lei $\mathrm{n}^{\mathrm{2}} 8.987$, em sua nova redação, também confirma que a concessão do serviço não depende da existência de via alternativa gratuita exceto se especificamente determinado por lei. Esse dispositivo confirma a viabilidade da imposição jurídica ou material - por ausência de alternativa — da compulsoriedade na utilização do serviço concedido.

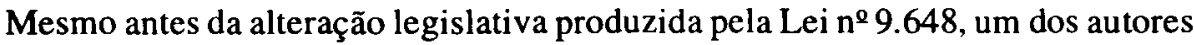
já havia escrito que "Existem serviços públicos compulsórios, na acepção de que o particular tem o dever de valer-se deles, em vista do interesse da coletividade. As 
hipóteses são excepcionais, em face dos princípios que estruturam um Estado Democrático de Direito. Assim, a ligação das residências à rede de água e esgoto não retrata uma livre escolha para os particulares" ${ }^{21}$.

Nunca se supôs, porém, que a compulsoriedade do serviço pudesse configurar obstáculo à sua prestação sob regime de concessão. Esse raciocínio contrariaria o art. 175 da Constituição Federal, que prevê amplamente a realização de serviços públicos sob regime de concessão sem excepcionar os serviços de limpeza urbana ou outros de utilização obrigatória. Também não seria compatível com os objetivos e valores constitucionais, que, em certos casos, pressupõem a obrigatoriedade de utilização do serviço público. Quando submetida a regime de concessão, que engloba disciplina destinada à proteção da lucratividade da exploração do serviço pelo concessionário, a prestação de serviços públicos de limpeza urbana enseja a cobrança de tarifa (não de taxa) pelo concessionário junto aos usuários dos serviços.

19.4. No mesmo sentido, manifestaram-se ANTÔNIO CARLOS CINTRA DO AMARAL ${ }^{21}$ e WERTHER BOTELHO ${ }^{22}$.

Enfim, o próprio CELSO ANTÔNIO BANDEIRA DE MELLO, um dos corifeus da Escola de Direito Público da PUC-SP, acabou por adotar idêntica concepção, tal como se vê em seu Curso de Direito Administrativo, Malheiros, $11^{\text {a }}$ ed., 1999, p. 525.

20. Ademais disso, a tese de que a concessão de serviço público seria remunerada através de taxa produz um impasse jurídico insuperável.

20.1. É da essência da concessão que o concessionário arque com o risco do empreendimento. $\mathrm{O}$ concessionário organiza empresarialmente o empreendimento visando à obtenção de lucro. A natureza jurídica da concessão é incompatível com a remuneração através de um tributo.

20.2. Para haver concessão, a cobrança e a administração do produto da arrecadação da taxa devem ser realizados diretamente pelo concessionário. A cobrança pela Administração Pública e o repasse dos valores correspondentes ao concessionário desvirtuaria, desde logo, o regime da concessão - que se caracteriza necessariamente pela ausência de pagamento direto do concessionário pela Administração Pública. A concessão supõe a possibilidade de o concessionário exigir diretamente dos usuários a remuneração pelos serviços.

Desse modo (admitindo-se, apenas para argumentar, que a remuneração do concessionário pudesse ter a natureza de taxa), a conjugação entre a disciplina da concessão e o regime jurídico da taxa exigiria a outorga ao concessionário da capacidade ativa para a cobrança do tributo frente aos seus sujeitos passivos. Ou seja, haveria situação de parafiscalidade (baseada em previsão de lei municipal que afetasse os recursos arrecadados através da taxa à remuneração do concessionário e outorgasse a este a capacidade para a cobrança, em nome próprio, da taxa).

20 JUSTEN, ob. cit., pp. 134/135.

21 "Concessão de Rodovias e Cobrança de Pedágio", em Estudos em Homenagem a Geraldo Ataliba, v. 2, Malheiros, 1997, p. 132.

22 Da Tributação e sua Destinação, Del Rey, 1994, p. 83. 
Ora, em autorizada monografia sobre o tema, ROQUE ANTONIO CARRAZZA nega a possibilidade de destinar-se o produto da arrecadação tributária a entidades privadas, cuja atuação fosse orientada à realização do lucro ${ }^{23}$.

$\mathrm{O}$ doutrinador define a parafiscalidade como "a atribuição, pelo titular da competência tributária, mediante lei, de capacidade tributária ativa, a pessoas públicas ou privadas (que persigam finalidades públicas ou de interesse público), diversas do ente impositor, que, por vontade desta mesma lei, passam a dispor do produto arrecadado, para a consecução dos seus objetivos" ${ }^{24}$. No mesmo estudo, o doutrinador aponta que a parafiscalidade pode beneficiar entes paraestatais ("pessoas jurídicas de direito privado que, pela natureza das atividades que desenvolvem (tipicamente estatais), sem fito de lucro, recebem do Poder Público especial amparo" ${ }^{25}$, mencionando que "Esta medida, exatamente pela índole dos entes beneficiados, não fere o princípio da destinação pública dos dinheiros arrecadados mediante tributos, que o Brasil, como a maioria dos países, adotou. Situação diversa ocorreria, se a parafiscalidade fosse estendida a outras pessoas jurídicas de direito privado, que não tivessem suas atividades norteadas para fins de interesse públi$\mathrm{co}^{20}$.

A situação do concessionário de serviço público é peculiar. Realiza suas atividades com o objetivo de perseguir interesse público. Há forte intervenção do Poder Público nas atividades do concessionário, seja na definição de metas, na fiscalização de seu cumprimento ou mesmo na alteração da concessão por ato unilateral do Poder Público. A persecução de interesse público é pressuposto da própria concessão: somente se admite a concessão de serviço público na medida em que seja definida (por opção legislativa) como o caminho adequado para a realização do interesse público na prestação adequada e eficiente dos serviços em questão.

Isso não exclui, porém, o aspecto de lucratividade da concessão - que justifica a participação privada em sua exploração. A concessão envolve legitimamente a busca de lucro pelo concessionário. Isso, aliás, está na base da qualificação jurídica de sua remuneração como tarifa: há garantia constitucional de preservação do equilíbrio entre expectativa de dispêndios e expectativa de ingressos traduzido na proposta de que terá derivado o contrato de concessão. As alterações subseqüentes podem conduzir a um desequilíbrio contra o qual está protegido o particular.

O concessionário persegue um duplo interesse: por um lado, o interesse público na prestação adequada do serviço; por outro, seu próprio interesse de lucro. $\mathrm{Na}$ medida em que mantenha a adequação do serviço, não lhe é vedado (ao contrário) reduzir custos e buscar eficiência de modo a obter a maior lucratividade do empreendimento - o que, em certos casos, deve reverter em benefício do usuário através da redução dos montantes cobrados (modicidade da tarifa) ou da ampliação dos serviços prestados. 
Haveria impossibilidade de se atribuir ao concessionário de serviço público a capacidade ativa para a exigência de taxa de serviço frente aos usuários. Além de eventual frustração do princípio da destinação pública do tributo, a remuneração do concessionário através de taxa envolveria obstáculo para a aplicação de princípios e regras peculiares à concessão (como a previsão de redução de tarifas em face de ganhos excepcionais do concessionário). Também sob esse ângulo, a rigidez do regime tributário seria incompatível com a prestação de serviço público mediante concessão.

20.3. Por outro lado, poder-se-ia supor alguma impossibilidade de produzir-se a quantificação da taxa. A base de cálculo da taxa de serviço deve corresponder ao custo total do serviço prestado pelo Estado. Como a remuneração paga pelo usuário do serviço envolve parcela de lucro do concessionário, em proporção não determinável de modo preciso quando da instituição da taxa, seria possível concluir que excede o mero custo do serviço prestado em favor do usuário (o que inviabilizaria sua utilização como base de cálculo para taxa de serviço).

Esse defeito, porém, é apenas aparente. É possível compreender o montante da remuneração do concessionário como o custo da atividade estatal — considerando-se que há a possibilidade de o Poder Público validamente optar pela prestação do serviço público sob regime de concessão. Essa constatação supera o problema relacionado com a base de cálculo da taxa. Persistem, porém, os dois outros pontos que impedem a remuneração do concessionário através de taxa.

20.4. Ou seja, afirmar que serviço público, ainda quando concedido, tem de ser remunerado através de taxa conduz à impossibilidade da concessão. A aplicação ampla do art. 145, inc. II, da CF/88 conduziria à ineficácia do art. 175. Mais ainda, estaria vedada a possibilidade de aplicação de um instituto explicitamente consagrado pela Constituição.

21. Por todos esse fundamentos, a remuneração do concessionário de serviços públicos de limpeza urbana somente pode ter a natureza jurídica de tarifa, não submetida ao regime tributário que caracteriza a taxa.

\section{VII. - Destinação específica de receita de imposto}

22. Deve-se investigar ainda a possibilidade de desmembramento de parcela do imposto sobre a propriedade territorial urbana (IPTU) e sua destinação ao custeio das atividades de limpeza urbana, bem como a viabilidade de o prestador de tais serviços promover diretamente e em nome próprio a cobrança de tal parcela de IPTU frente aos usuários.

22.1. Esse desmembramento de parcela do IPTU corresponderia a uma das possibilidades de financiamento das atividades de limpeza urbana.

Como já se apontou, nada impede que os serviços de limpeza urbana sejam objeto de concessão. Nesse caso, a remuneração do concessionário corresponderia a tarifa, sujeita às regras de direito administrativo (inclusive a subordinação à lei). Havendo concessão de serviço público, os montantes cobrados dos usuários dos serviços são obrigatoriamente caracterizados como tarifa por aplicação dos arts. 37 , 
XXI, e 175 da Constituição de 1988. A opção do Poder Público estará entre a prestaçāo direta dos serviços e a sua prestação em regime de concessão. Havendo opção pelo regime de concessão, a remuneração do concessionário somente poderá ter a natureza de tarifa.

22.2. Na hipótese de prestação dos serviços (específicos e divisíveis) pela Administração Pública e sob regime diverso do de concessão, haverá opção legislativa entre a instituição de taxa a ser cobrada dos beneficiários dos serviços ou a ausência de cobrança vinculada à prestação dos serviços. Como já se apontou, essa opção não é inteiramente livre, mas é informada pelo princípio da capacidade contributiva. Ofenderia o princípio da isonomia e frustraria o princípio da capacidade contributiva a prestação estatal (sob a forma de serviço) que beneficiasse de modo especial certos particulares sem a cobrança de compensação econômica correspondente (salvo razões de interesse público). A regra, portanto, será a instituição de taxa vinculada à prestação de tais serviços.

A segregação de uma parcela do montante arrecadado através do IPTU para o custeio das atividades de limpeza urbana assume relevância no caso da prestação dos serviços sob regime diverso do de concessão e sem que seja instituída taxa vinculada aos ditos serviços (por mera opção legislativa ou por não se tratar de serviços específicos e divisíveis).

Note-se que o custeio das atividades de limpeza urbana não guarda nenhuma relação necessária com a receita do IPTU. Esse imposto está, em relação às atividades de limpeza urbana, em situação idêntica à de todas as demais fontes de receita municipal. A circunstância de se tratar de imposto que tem por hipótese de incidência a propriedade imobiliária em nada altera o exame da viabilidade da afetação de parte da receita derivada de sua arrecadação. Na medida em que seja cabível a afetação de receita, poderá envolver a receita de qualquer imposto (IPTU, ISS ou ITBI) ou mesmo dos valores oriundos das transferências constitucionais promovidas pela União ou pelos Estados em favor dos Municípios.

23. A primeira condição para que se possa cogitar da segregação de parte do valor do IPTU (ou de outra receita municipal) para o custeio das atividades de limpeza urbana é a ausência de concessão dos serviços.

Para que possa haver esse desmembramento, a participação da pessoa privada na realização desses serviços deve ser a de contratada da Administração Pública, não de concessionária.

O contratado (não concessionário) tem seus deveres e a remuneração correspondente claramente quantificados no contrato de prestação de serviços. Há a previsão explícita do montante da remuneração do contratado. Não há a possibilidade de, na ausência de fatos supervenientes, ser promovida a redução da remuneração do contratado (exceto se observados limites legais e em face de correspondente redução dos encargos do contratado).

A prestação de serviços de limpeza urbana por ente diverso da Administração Pública sob regime de mera contratação (não de concessão) corresponde à realização direta dos serviços pelo Poder Público (na redação do art. 175 da Constituição de 1988). 
Nesse mesmo caso, nada impediria que se vinculasse a tais serviços (desde que específicos e divisíveis) a exigência de uma taxa. Porém, é outro o tema específico ora em exame.

24. Em segundo lugar, a previsão de custeio dos serviços de limpeza urbana através da receita de impostos (inclusive o IPTU) pressuporia a ausência de especificidade e divisibilidade de tais serviços.

Os serviços de remoção e destinação final de lixo são específicos e divisíveis. É possível, por critérios técnicos, apurar com grande aproximação quem são os usuários dos serviços e a quantidade de serviço dirigida a cada qual.

$\mathrm{Na}$ hipótese de não haver a concessão do serviço, deve ser instituída taxa a ele vinculada. O seu custeio através de receita de impostos (especialmente se houver a segregação de uma parte do produto da arrecadação do imposto para a cobertura desses serviços) representaria ofensa ao princípio da capacidade contributiva. Afinal, a generalidade dos proprietários de imóveis (no caso do IPTU) custearia atuação estatal que beneficiaria apenas determinadas pessoas. Haveria frustração do princípio da capacidade contributiva tanto subjetivamente (em relação às pessoas atingidas pelo tributo) quanto objetivamente (em face do montante exigido de cada qual).

São relevantes, porém, as opiniões acerca da ausência de especificidade e divisibilidade de todas ou de algumas das atividades envolvidas na limpeza urbana (conforme já referido, essa é a orientação predominante nos Tribunais Superiores). É possível - inclusive em face da necessidade de certeza na arrecadação - que a lei municipal opte pela não instituição de taxa e pelo custeio da limpeza urbana através de receitas de outras fontes.

25. O principal obstáculo que se poderia levantar contra a segregação e a afetação de parte da arrecadação do IPTU seria a proibição de afetação de receita de impostos contida no art. 167, IV, da Constituição de 1988 ("a vinculação de receita de impostos a órgão, fundo ou despesa, ...").

25.1. A regra já estava contida, com conteúdo parcialmente diverso, no art. 62, $\S 2$, da Constituição de $1967 / 1969$. O dispositivo da $C F / 88$ restringiu a vedação apenas aos impostos, não a outras espécies tributárias nem a receitas derivadas de transferências constitucionais - confiram-se sobre esse ponto IVES GANDRA MARTINS $^{27}$ e EUNICE COSTA ${ }^{28}$.

Essa disposição traduz a noção de um fundo único na elaboração do orçamento, que não é peculiar ao direito brasileiro. Sobre disposição similar na lei de orçamentos da Argentina, HÉCTOR VILLEGAS alude ao princípio de "não afetação de recursos", cujo objeto é o de que "determinados recursos não se utilizem para a atenção de gastos determinados, isto é, que não tenham uma 'afetação especial', mas ingressem nas rendas gerais, de modo tal que todas as receitas entrem em um fundo comum e sirvam para financiar todas as despesas" ${ }^{29}$. No mesmo sentido, confira-se GIULIANI FONROUGE ${ }^{30}$.

27 Comentários à Constituiçāo do Brasil, Saraiva, v. 6, 1991, p. 344.

28 "Vinculação da Receita - Transferência - Possibilidade", RDP n 97, p. 259.

29 Curso de Finanzas, Derecho Financiero y Tributario, Depalma, $5^{\mathrm{a}}$ ed., 1994, p. 794.

30 Derecho Financiero, Depalma, 5 ed., v. I, 1993, pp. 193/194 
MANOEL GONÇALVES FERREIRA FILHO menciona que "Prevalece aqui o princípio da unidade de caixa, um dos aspectos do princípio da unidade orçamentária. Todas as receitas, em virtude desse princípio, convergem para um fundo geral" ${ }^{31}$. PONTES DE MIRANDA ressalta a ampla possibilidade de, no texto constitucional anterior, haver arrecadação vinculada "Ou porque se trate de imposto único, ou porque a própria Constituição o haja previsto ou estabelecido, ou porque conste de lei complementar" 32 .

Ao explicar o sentido da regra, VILLEGAS anota que a instituição de impostos com afetação especial pode resultar de pressões setoriais "para estabelecer leis permanentes de gastos com receitas fixas que os favoreçam, criando-se por isso muitas vezes 'desperdícios' de recursos e provocando a ineficácia dos mecanismos orçamentários" ${ }^{33}$. A criação de um fundo único orçamentário buscaria evitar a estipulação de despesas em valor estabelecido de modo definitivo, o que poderia conduzir a um gasto superior ao necessário.

Em estudo sobre a destinação ambiental dos impostos, JOSÉ MARCOS DOMINGUES DE OLIVEIRA aponta as dificuldades sobre a matéria e a necessidade de reforma da Constituição para admitir-se tal resultado ${ }^{34}$.

25.2. No entanto, a segregação de parte da arrecadação do IPTU para o custeio dos serviços de limpeza urbana não se enquadra na proibição de destinação de receita de impostos para órgão, fundo ou despesa. $O$ que se proíbe é a vinculação, não a mera dissociação por ocasião da arrecadação.

25.3. Observe-se que a vedação constitucional visa a permitir a administração dos recursos orçamentários pela Administração Pública quando da execução do orçamento e evitar o desperdício de recursos com a vinculação a um certo fim de recursos em montante eventualmente superior ao necessário.

Essa finalidade não seria frustrada com a segregação pretendida. Em primeiro lugar, trata-se de serviços essenciais, diretamente vinculados à dignidade humana $\mathrm{e}$ de prestação obrigatória para o Poder Público. Depois, a remuneração do contratado deve ser definida em contrato administrativo que atenda aos requisitos legais (inclusive quanto ao montante da remuneração) - o que elimina o risco relacionado com o desperdício de recursos.

A regra do art. 167, IV, da Constituição de 1988 destina-se a impedir a afetação de um montante incerto e aleatório (como a totalidade ou um percentual pré-definido da arrecadação de um imposto) a uma determinada finalidade. Com isso, haveria incerteza do montante da despesa - a qual corresponderia, em última análise, ao valor aleatório da receita. Ademais, haveria desperdício na hipótese de a arrecadação do imposto resultar em montante superior ao previamente estimado (hipótese em

31 Comentários à Constituiçāo Brasileira, Saraiva, 6a ed., 1986, p. 332.

32 Comentários à Constituição de 1967/1969, RT, t. III, $2^{\mathrm{a}}$ ed., 1973, p. 207.

33 Ob. cit., p. 794.

34 "Meio Ambiente - Tributação e Vinculação de Impostos", em Revista de Direito Tributário $n^{2} 56 / 84$. 
que os recursos permaneceriam vinculados a uma despesa para a qual seriam já desnecessários).

Nem o desperdício nem a incerteza ocorrem, contudo, se a segregação do valor do IPTU for vinculada ao montante da remuneração fixada no contrato administrativo. Nesse caso, o contratado receberia apenas o montante fixado no contrato. A única peculiaridade é a de que a fonte de tais recursos (receita de IPTU, por exemplo) já seria definida previamente. Assim, a lei municipal poderia estipular que a receita de IPTU, até um determinado valor (correspondente ao definido no contrato administrativo), seria afetada ao custeio dos serviços de limpeza urbana (ou seja, ao pagamento da remuneração do contratado para a execução de tais serviços).

Nessa situação, porém, a arrecadação do IPTU continuaria a competir ao Município, que repassaria ao contratado o montante correspondente à sua remuneração.

26. Enfim, a regra constitucional não impede a parafíscalidade. Não se impede que a lei atribua a capacidade tributária ativa a um certo sujeito, o qual realiza a arrecadação em nome próprio e se aproprie do produto arrecadado para realizar determinados fins.

Essa é a outra hipótese cabível: a conjugação entre a afetação de parte da receita do imposto e a atribuição ao contratado da capacidade tributária ativa para a arrecadação dessa parcela (parafiscalidade).

26.1. Seria o caso em que a lei municipal atribuísse ao concessionário o dever de arrecadar o IPTU, com previsão de que uma parte do montante arrecadado seria de sua titularidade e o remanescente deveria ser repassado aos cofres públicos. Nesse caso, a situação jurídica do contratado frente à cobrança do tributo (imposto) seria dúplice. Em relação ao valor da remuneração contratual do contratado, haveria parafiscalidade. Quanto ao restante, o contratado seria agente arrecadador ${ }^{35}$ - com o dever de entregar ao Município o produto da arrecadação.

26.2. Como já se destacou, há intensa disputa sobre a possibilidade de se atribuir a capacidade tributária ativa (em regime de extrafiscalidade) a pessoas privadas. Ao se examinar a parafiscalidade na cobrança de taxas pelo concessionário, concluiu-se pela sua inadmissibilidade.

A situação do contratado para a execução do serviço, porém, é distinta da do concessionário do serviço público. O montante que deverá ser arrecadado e administrado pelo contratado corresponde precisamente à remuneração que já lhe é assegurada por contrato administrativo. Não há nenhum desvio em relação à destinação pública do tributo. Há mera participação do contratado também na arrecadação do montante necessário para o custeio dos serviços por ele prestados.

Note-se que essa participação em nada altera a situação do contratado em relação ao contrato para a execução dos serviços. Por não se tratar de concessão, o contratado não assume nenhum risco relacionado com a arrecadação do imposto. Se o montante da arrecadação for insuficiente, por qualquer motivo, caberá ao Poder Público efetuar o pagamento da remuneração contratual com outros recursos. Isso não significa a possibilidade de o contratado ser desidioso ao promover a arrecadação. A lei muni- 
cipal e o próprio contrato de execução dos serviços devem prever os deveres do contratado em relação à arrecadação do imposto - inclusive dispondo sobre penalidades aplicáveis ao contratado.

27. Desse modo, a afetação de parte da arrecadação do IPTU, nas condições acima referidas, não é proibida pelo art. 167, IV, da Constituição Federal. Quanto a eventual taxa de serviço, nem sequer se põe a dúvida, tendo em vista que a redação do dispositivo constitucional exclui as taxas da proibição de afetação.

Para a validade da afetação e da instituição de regime de parafiscalidade (com atribuição de capacidade tributária ativa ao executor dos serviços), os serviços devem ser prestados em regime de contratação de serviços, não de concessão (nem permissão). Além disso, devem ser atendidas as seguintes condições: (a) não ser prevista a destinação vinculada de percentual fixo da receita mas do valor em dinheiro estipulado no contrato de prestação de serviços como remuneração do contratado, (b) na hipótese de a lei atribuir capacidade ativa para que o contratado promova a arrecadação de parte ou de todo o imposto, existir a previsão legal de repasse pelo contratado ao Poder Público do montante arrecadado que exceder a remuneração prevista no contrato de prestação de serviços, e (c) o risco na arrecadação ser assumido pelo Poder Público, não pelo contratado (embora seja cabível a previsão de rescisão do contrato na hipótese de descumprimento de obrigações do contratado atinentes à arrecadação dos tributos).

\section{VIII. - Conclusões}

28. Os tópicos acima permitem concluir que os serviços de limpeza urbana (coleta, remoção e destinação de lixo urbano) consistem em serviços públicos passíveis de concessão. A sua essencialidade e a necessidade de adoção de critérios complexos para a identificação de um usuário individual não impedem a sua concessão.

Além disso, o regime de concessão de serviços públicos, ao incorporar a determinação constitucional de preservação da equação econômico-financeira do contrato de concessão, excepciona o regime de direito tributário e determina que a contraprestação seja realizada através de tarifa, sujeita ao regime de direito administrativo, em lugar de taxa, submetida ao regime tributário. É juridicamente impossível a cobrança de taxa diretamente pelo concessionário, em regime de parafiscalidade o que confirma a conclusão de que a cobrança apenas pode ter a natureza de tarifa.

Nada impede a segregação de parte da arrecadação do IPTU para esse fim no caso de contratação de serviços, não no de concessão. A concessão envolve a assunção de risco pelo concessionário, que é remunerado através de tarifa que the cabe cobrar diretamente dos usuários. Não é possível que a remuneração do concessionário seja custeada pelo Poder Público. No caso de contratação de serviços, a segregação de parte da arrecadação do IPTU ao custeio dos serviços de coleta e disposição final de lixo não é vedada pelo art. 167, IV, da Constituição Federal, desde que atendidas as seguintes condições: (a) ausência de previsão de destinação de um percentual fixo da receita arrecadada mas de um valor em dinheiro, estipulado 
no contrato de prestação de serviços como remuneração do contratado, (b) na hipótese de parafiscalidade, previsão legal do repasse pelo contratado do montante arrecadado que exceder a remuneração prevista no contrato de prestação de serviços, e (c) assunção do risco na arrecadação pelo ente político, não pelo contratado (embora seja cabível a previsão de rescisão do contrato na hipótese de descumprimento de obrigações do contratado atinentes à arrecadação dos tributos).

Por fim, conclui-se que se autoriza ao concessionário de serviços de limpeza urbana cobrar, em nome próprio e diretamente dos usuários, a contraprestação pelos serviços (tarifa). Já o contratado para a realização desses serviços pode deter capacidade ativa para a arrecadação de taxa ou imposto e seu repasse integral ou parcial ao Município contratante (desde que prevista essa atribuição em lei municipal). Nesse caso, o contratado exerceria a capacidade tributária ativa em regime de parafiscalidade (em relação ao montante destinado ao custeio dos serviços de limpeza urbana) e como agente de arrecadação (em relação à parcela da taxa ou imposto que devesse ser repassada ao Município contratante). 